\title{
Safety Issues Associated with Paclitaxel-Eluting Balloons and Progress of Sirolimus-Eluting Balloons
}

\author{
Yu Xia Yin ${ }^{1,2}$, Zhi Yong Wang ${ }^{3}$, Lu Ning Wang ${ }^{2}$, Ming Kun Cao ${ }^{1}$, Tian Heng Lu ${ }^{1}$, \\ Hai Jun Zhang ${ }^{1,4,5, *}$ \\ ${ }^{1}$ National United Engineering Laboratory for Biomedical Material Modification, Dezhou, China \\ ${ }^{2}$ School of Materials Science and Engineering, University of Science and Technology, Beijing, China \\ ${ }^{3}$ Department of Emergency, Inner Mongolia people's Hospital, Hohhot, China \\ ${ }^{4}$ Department of Vascular \& Intervention, Tenth Peoples' Hospital of Tongji University, Shanghai, China \\ ${ }^{5}$ Department of Health Science and Technology, Faculty of Medicine, Aalborg University, Aalborg, Denmark \\ Email address: \\ zhanghaijun@tongji.edu.cn (Hai Jun Zhang) \\ ${ }^{*}$ Corresponding author
}

\section{To cite this article:}

Yu Xia Yin, Lu Ning Wang, Ming Kun Cao, Tian Heng Lu, Hai Jun Zhang. Safety Issues Associated with Paclitaxel-Eluting Balloons and Progress of Sirolimus-Eluting Balloons. International Journal of Cardiovascular and Thoracic Surgery. Vol. 6, No. 5, 2020 , pp. 54-59. doi: $10.11648 /$ j.ijcts.20200605.11

Received: February 1, 2020; Accepted: September 14, 2020; Published: September 19, 2020

\begin{abstract}
Drug eluting balloons (DEBs) are semi-compliant angioplasty balloons covered with an antiproliferative drug which is rapidly released locally into the vessel wall during balloon contact. Their advantages include a broader area of drug contact, more homogenous drug-tissue transfer for stent-based local drug delivery, no implant leaving as well as shortened dual antiplatelet therapy. DEBs application was first recommended by the European Society of Cardiology (ESC) and European Association for Cardio-Thoracic Surgery (EACTS) guidelines for the treatment of in-stent restenosis (ISR) after prior bare-metal stent (BMS) (Class IIA, Level B) in 2010. Since then, rapid progress has been made in the use of DEBs for treatment of in-stent restenosis, bifurcation, small vessel diseases, and other de novo occlusive coronary artery diseases even the symptomatic peripheral arterial disease. However, a meta-analysis of 28 randomized controlled trials (RCTs) with 4663 patients investigating paclitaxel-coated devices (DEBs \& drug-eluting stent) in the femoral and/or popliteal arteries showed a highly significant association between risk of death and paclitaxel exposure in a dose-time-dependent manner. Safety issues associated with clinical application of paclitaxel DEBs in femoropopliteal artery was widely discussed. This study reviewed the issues, different molecular mechanisms of paclitaxel and sirolimus in antiproliferative effects, and progress of sirolimus-eluting balloons.
\end{abstract}

Keywords: Drug Eluting Balloons, Paclitaxel-Eluting Balloons, Sirolimus-Eluting Balloons

\section{Introduction}

Since the 1970s, the invention of balloon angioplasty and percutaneous coronary intervention (PCI) have made rapid progress in treatment of occlusive coronary artery disease (CAD). Drug eluting balloons (DEBs) are semi-compliant angioplasty balloons covered with an antiproliferative agent that is rapidly released locally into the vessel wall during balloon contact [1]. They allow a broader area of surface contact and more homogenous drug-tissue transfer for stent-based local drug delivery. DEB application was first recommended by the European Society of Cardiology (ESC) and European Association for Cardio-Thoracic Surgery (EACTS) guidelines for the treatment of in-stent restenosis (ISR) after prior bare-metal stent (BMS) (Class IIA, Level B) in 2010 [2]. Then, DEB was recommended by the ESC/EACTS guidelines for the treatment of in-stent restenosis (ISR) (within BMS or DES, Class IA) in 2014 [3] and 2018 [4]. Besides ISR, DEBs have demonstrated safety and efficacy in the treatment of bifurcation, small vessel diseases, and other de novo CADs in a number of clinical trials $[1,5]$. Furthermore, DEB research on the treatment of 
symptomatic peripheral artery disease has also been performed with favorable outcomes. The U.S. has also approved paclitaxel-eluting balloons for peripheral artery disease (PAD) above the knee. Table 1 illustrates the characteristics of different paclitaxel-coated balloons in PAD. However, a recent meta-analysis of randomized clinical trials warranted the increased risk of long-term mortality following application of paclitaxel-coated balloons and stents in the femoropopliteal artery of the lower limbs [6]. In addition, clinical analysis of a paclitaxel stent (Boston Scientific, Marlborough, MA) showed a significant increase in long-term death and myocardial infarction after one year following implantation [7, 8]. A five-year follow-up study and randomized comparison studies on paclitaxel and sirolimus DESs further confirmed these events [9-12]. Consequently, paclitaxel DES has been shown to result in vessel wall tissue inflammation, aneurysm formation, and late stent thrombosis, eventually delisting from the coronary field [13, 14]. Therefore, more studies should investigate paclitaxel-coated balloon safety, different molecular mechanisms of paclitaxel and sirolimus in antiproliferative effects, as well as progress in treatment with sirolimus-eluting balloons. This study reviewed the conflict issues, different molecular mechanisms of paclitaxel and sirolimus in antiproliferative effects, and progress of sirolimus-eluting balloons to put a forward to the DEBs research and application.

Table 1. Design characteristics of paclitaxel-eluting balloons in PAD.

\begin{tabular}{|c|c|c|c|c|}
\hline Brand name & Paclitaxel dose & Excipient/spacer & Manufactor (Country) & Indication \\
\hline IN.PACT & $3.5 \mu \mathrm{g} / \mathrm{mm}^{2}$ & Urea & Medtronic (US) & $\begin{array}{l}\text { De novo FP and TP } \\
\text { stenosis, ISR in SFA }\end{array}$ \\
\hline Passeo-18 Lux & $3.0 \mu \mathrm{g} / \mathrm{mm}^{2}$ & Butyryl-tri-n-hexyl citrate (BTHC) & Biotronik (Germany) & De novo FP stenosis \\
\hline Lutonix & $2.0 \mu \mathrm{g} / \mathrm{mm}^{2}$ & Polysorbate and sorbitol & Becton Dickinson (US) & De novo FP stenosis \\
\hline Ranger & $2.0 \mu \mathrm{g} / \mathrm{mm}^{2}$ & acetyl tributyl citrate - ATBC (Transpax) & Boston Scientific (US) & FP and IP stenosis \\
\hline Freeway & $3.0 \mu \mathrm{g} / \mathrm{mm}^{2}$ & Shellac & Eurocor (Germany) & FP and IP stenosis \\
\hline LegFlow & $3.0 \mu \mathrm{g} / \mathrm{mm}^{2}$ & Nanocrystalline $0.1-\mu \mathrm{m}$ paclitaxel in ammonium salt & Cardionovum Germany) & SFA and BTK stenosis \\
\hline Cotavace & $3.0 \mu \mathrm{g} / \mathrm{mm}^{2}$ & Paccocath (Iopromide iodinated contrast) & Lubrizol (US) & De novo FP stenosis \\
\hline Luminor & $3.0 \mu \mathrm{g} / \mathrm{mm}^{2}$ & Organic ester & iVascular (Spain) & FP and IP stenosis \\
\hline Stellarex & $2.0 \mu \mathrm{g} / \mathrm{mm}^{2}$ & Polyethylene glycol & Philips (Holland) & FP and IP stenosis \\
\hline Primus & $3.0 \mu \mathrm{g} / \mathrm{mm}^{2}$ & Shellac & Cardionovum (Poland) & FP and IP stenosis \\
\hline
\end{tabular}

FP: Femoropopliteal; TP: Tibialpedal; IP: Infrapopliteal; SFA: Superficial femoral artery; BTK: Below-the-knee.

\section{Safety Issues: Paclitaxel DEB in Femoropopliteal Artery}

A meta-analysis of 28 randomized controlled trials (RCTs) with 4663 patients investigating paclitaxel-coated devices in the femoral and/or popliteal arteries was published in the Journal of the American Heart Association [6]. The results showed that all-cause patient death at one year (28 RCTs with 4432 cases) was similar between paclitaxel-coated devices and control arms (2.3 vs. 2.3\%). All-cause death at two years (12 RCTs with 2316 cases) was significantly increased in the case of paclitaxel vs. control (7.2 vs. 3.8\%) with an increased relative risk ratio of $68 \%$. All-cause death up to five years (3 RCTs with 863 cases) increased further in the case of paclitaxel (14.7 vs. $8.1 \%$ ) with an increased relative risk ratio of $93 \%$. Random effects meta-regression analysis was proposed, identifying a highly significant association between risk of death and paclitaxel exposure in a dose-time-dependent manner. However, a nationwide, multicenter, retrospective cohort study including 16,560 patients from 1883 medical centers who were admitted for femoropopliteal artery revascularization was performed to verify the above conclusion [15]. After a multivariable statistical analysis, drug-coated devices were not associated with a difference in all-cause mortality compared to non-drug-coated devices. In addition, an independent patient-level meta-analysis was conducted based on four IN.PACT trials, where no statistically significant differences were observed in all-cause mortality between DEBs and percutaneous transluminal angiography (PTA) over the course of 5 years (9.3 vs. 11.2\%) [16]. No deaths were adjudicated by an independent clinical event committee as device-related. This finding was also supported by other published research $[17,18]$. Warnings were proposed by the American Food and Drug Administration (FDA) for the applications of DEBs for femoropopliteal artery revascularization. Although essential result components of current studies for safety evaluation of DEB/DES are still pending, the FDA has stated that "The benefits continue to outweigh the risks for approved paclitaxel-coated balloons and paclitaxel-eluting stents when used in accordance with their indications for use" and that "Decision to use such devices should only be made only after full disclosure of the potential adverse outcomes to patients for whom their use is clearly indicated" [19]. More studies are needed to assess the magnitude of increased mortality, causality, and patient sub-groups at risk. Many aspects may impact clinical outcomes and safety concerns should not be ignored.

Paclitaxel DES had been reported to have a significantly higher cardiovascular mortality compared to sirolimus DES when used in cardiology PCI, possibly caused by vessel wall tissue inflammation, aneurysm formation, and late stent thrombosis [20-22]. The possible reasons were thoroughly investigated using in vitro cell cytotoxicity assays and autopsy of animals and patients implanted with paclitaxel DESs. The dramatic differences in molecular mechanisms by which sirolimus or paclitaxel affect smooth muscle cell proliferation contributed to adverse cardiovascular events. Sirolimus is a 
macrocyclic antibiotic immunosuppressant produced by Streptomyces hygroscopicus that binds to the immunophilin FK-506 binding protein-12 (FKBP-12). The resulting sirolimus/FKBP-12 complex inhibits the kinase activity of mammalian target of rapamycin, subsequently reducing the activity of multiple kinases associated with mitogen-induced cell proliferation $\left(\mathrm{P} 70^{\mathrm{s} 6 \mathrm{k}}\right.$, cyclin $\left.\mathrm{E} / \mathrm{CDK}-2\right)$. This process leads to cell cycle arrest at the $\mathrm{G} 1 / \mathrm{S}$ transition point without inducing apoptosis. In addition, the antiproliferative effect can be reversed upon drug washout [23, 24]. More importantly, sirolimus is an immunosuppressive agent that blocks the inflammatory response in infants. By contrast, paclitaxel is a naturally occurring antineoplastic agent that is extracted from Taxus brevifolia bark. It achieves its antiproliferative effects by disrupting microtubule dynamics through binding to the aminoterminus of $\beta$-tubulin, preventing normal microtubule depolymerization and subsequently resulting in cell arrest in the $\mathrm{M}$ phase of the cell cycle and cell death $[25,26]$. Moreover, the antiproliferative effects of paclitaxel are more durable and highly effective than those of sirolimus, inhibiting migration of smooth muscle and endothelial cells, which is critical for reestablishment of a functional endothelium following coronary artery stenting [27]. Delayed endothelialization may cause sustained inflammation and stent thrombosis.

Coating properties are determined by the crystal state of paclitaxel, type of excipient, and manufacturing process and also need to be considered. An intact arterial wall poses a significant barrier to drug penetration. About $80-90 \%$ of the drug load may remain unabsorbed. Increased paclitaxel crystallinity helps achieve a higher tissue uptake and retention and improved biological effect. However, the crystallized paclitaxel may increase the microparticle formation which may embolize in the downstream systemic circulation. (Figure 1). But amorphous paclitaxel cannot be used because it is easily washed out into the blood. Drug over-uptake in a local vessel can also result in neointimal inhibition, sustained inflammation, and stent thrombosis. In the early stages of paclitaxel DEB development, safety profile of this first-generation technology was questioned due to high amounts of coating particulate produced following balloon inflation. A comparative drug-coated balloon study in the familial hypercholesterolemic swine model of superficial femoral in-stent restenosis has been conducted to evaluate the impact of paclitaxel dose on tissue pharmacokinetics and vascular healing [13]. Results showed that compared to a lower paclitaxel density $\left(2 \mu \mathrm{g} / \mathrm{mm}^{2}\right)$, a higher paclitaxel density $\left(3 \mu \mathrm{g} / \mathrm{mm}^{2}\right)$ exhibited slightly higher levels of neointimal inhibition, reduced neointimal maturity, and higher fibrin deposition, suggesting that reduced paclitaxel density leads to a slightly lower neointimal inhibition but better healing profiles.

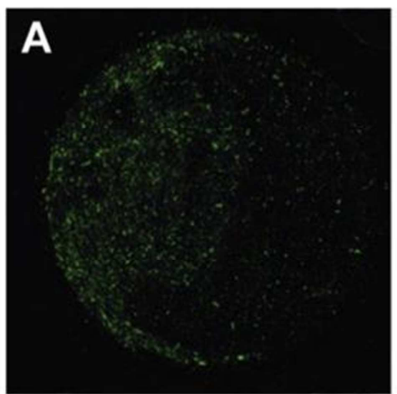

Ranger

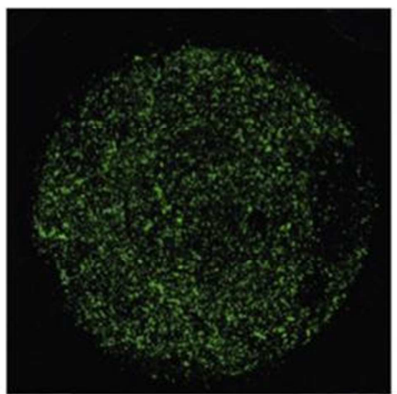

Lutonix

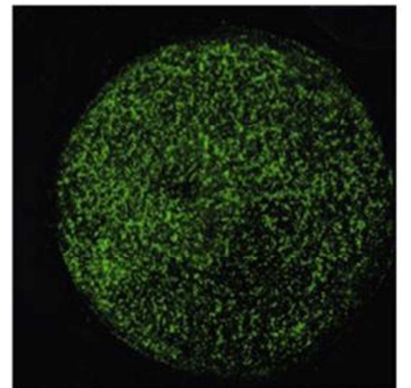

In.Pact pacific
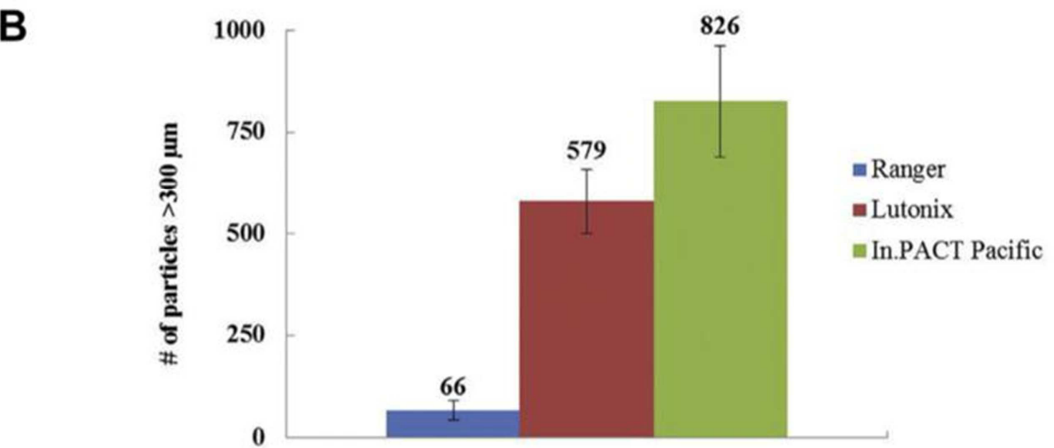

Figure 1. Particulate formation following paclitaxel balloon inflation [13]. (A) Qualitative appearance of coating particulate produced by each tested drug-coated balloon. (B) Quantitative analysis including particles $\geq 300 \mu \mathrm{m}$ in size. Ranger PCB $\left(2 \mu \mathrm{g} / \mathrm{mm}^{2}\right)$ employs acetyl tributyl citrate as excipient. IN.PACT $P C B\left(3 \mu \mathrm{g} / \mathrm{mm}^{2}\right)$ uses urea as excipient. Lutonix $P C B\left(2 \mu \mathrm{g} / \mathrm{mm}^{2}\right)$ uses non-polymer-based poly-sorbate/sorbitol as excipient.

\section{Sirolimus-Eluting Balloons}

The ideal DEBs are defined as those achieving a uniform coating that minimizes the quantity of particles released and provides maximal drug retention with minimal vascular toxicity. Paclitaxel is the first choice for good lipophilicity and tissue retention characteristics. Technological developments in the DEB field continue to evolve. Many companies and institutions have started to research and 
manufacture various sirolimus DEBs.

Polymer-free phospholipid encapsulated sirolimus nanocarriers have been introduced into the process of controlled drug release (Figure 2) [28]. Nanoparticles provide a stable and homogenous coating for the DEBs (Magic Touch, Concept Medical Research Private Limited, India). A nominal drug dose is $\sim 1.27 \mu \mathrm{g} / \mathrm{mm}^{2}$. Pre-clinical assessment of safety and efficacy showed that the most appropriate identification of the best nanoparticle structure is associated with an extremely efficient drug transfer to all layers of the vessel wall, achieving high tissue concentrations that persisted for days after the application, with low systemic drug leaks [29]. The Nanoluté registry was designed to observe the clinical performance of Magic Touch for the treatment of coronary de novo and restenotic lesions [30]. A total of 394 Magic Touch DEBs at Indian centers were used in 332 patients to treat 356 lesions. In-stent restenosis and small coronary vessel disease occurred in 46 and $43 \%$ of the patients, respectively. Mean balloon length and diameter (average $\pm \mathrm{SD}$ ) were $21.83 \pm 6.70$ $\mathrm{mm}$ and $2.69 \pm 0.45 \mathrm{~mm}$, respectively. All patients with data for the one-year follow-up were included. Overall major adverse cardiac event (MACE) rate was $4.2 \%(\mathrm{n}=14)$, which included deaths $(0.3 \%, \mathrm{n}=1)$, target lesion revascularization (TLR) $(3.6 \%, \mathrm{n}=12)$, and myocardial infarction $(0.3 \%, \mathrm{n}=1)$. Magic Touch DEBs was approved by the CE mark in 2016. In a multicenter, prospective, and real-world study, 438 patients were included, with a total of 516 PCI procedures on 465 lesions, all treated with Magic Touch DEBs [31]. Of the 465 lesions, $45.81 \%$ were in-stent restenotic lesions, where de novo accounted for $54.19 \%$. Among those de novo lesions, $43.87 \%$ were located in small coronary vessels (reference vessel diameter, RVD $2.75 \mathrm{~mm}$ ). MACE rates were 4.33, 5.1, and $7.72 \%$ at 1,2 , and 3 years, respectively. There were no increments in events at 2- and 3-year follow-ups.

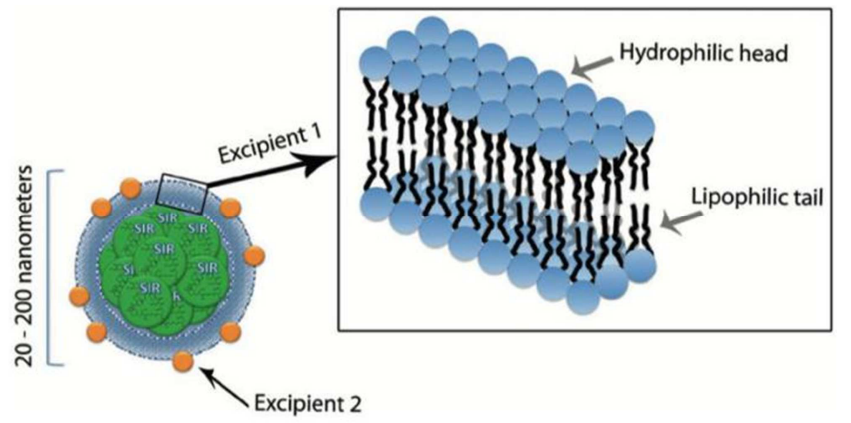

Figure 2. Schematic illustration of nanoparticle ultrastructure containing sirolimus (nucleus, in green) and incorporating combination of two excipient carriers to allow penetration and release of active agent [28]. Excipient 1 is a lipid-based component with a hydrophilic head and two lipophilic tails, which is the basic unit of a bilayer membrane that encapsulates the particle (note the detail in the right upper panel). Excipient 2 is integrated in the particle envelope, comprising $\sim 5 \%$ of the coating mass. It is a calcium-phosphorus-based component with enhanced hemocompatibility that is readily absorbed into the vessel wall and releases the encapsulated drug upon variation in $\mathrm{pH}$.

The sequent please paclitaxel-coated balloon was the first and most widely used deb in cad. A novel sequent sirolimus deb was fabricated with a drug concentration of $4 \mu \mathrm{g} / \mathrm{mm} 2$ (figure 3) [32]. A randomized, multicenter trial enrolling 50 patients has been proposed to compare safety and efficacy [33]. A quantitative coronary angiography at six months revealed that in-segment late lumen loss was $0.21 \pm 0.54 \mathrm{~mm}$ in the paclitaxel deb group vs. $0.19 \pm 0.56 \mathrm{~mm}$ in the sirolimus deb group. No differences were observed in clinical events between the groups.

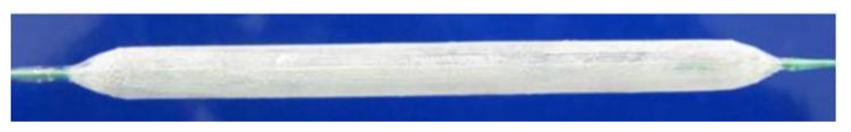

Figure 3. Sirolimus-coated balloon, $\mathrm{Vb}$ coating with a dose of $4 \mu \mathrm{g} / \mathrm{mm}^{2}$ on SeQuent Neo balloon platform. Vb indicates crystalline sirolimus coating [32].

The SELUTION DEB (Med Alliance SA, CH) uses sirolimus-containing poly (lactic-co-glycolic acid) (PLGA) microspheres in a phospholipid transfer membrane. The microspheres are transferred by balloon expansion to the vessel wall and provide a sustained drug release similar to a DES [34]. Detailed technical parameters and clinical results of these studies are not available yet.

Design of the Virtue sirolimus-eluting angioplasty balloon (Caliber Therapeutics, New Hope, Pennsylvania) is completely different from the above-mentioned sirolimus DEBs [35]. It combines a promising approach involving encapsulation of sirolimus in submicron particles with angioplasty without a balloon coating (Figure 4). Thus, a liquid formulation is delivered through precise micropores in the balloon concurrently with angioplasty [36]. In a single-arm feasibility study at 9 European centers, 50 ISR patients were treated with the Virtue balloon. The in-segment late lumen loss at six months was $0.31 \pm 0.52 \mathrm{~mm}$. The MACE rates were $10.2 \%$ and $14.3 \%$ at six months and one year, respectively, underscoring the need for further evaluation of dedicated randomized studies.

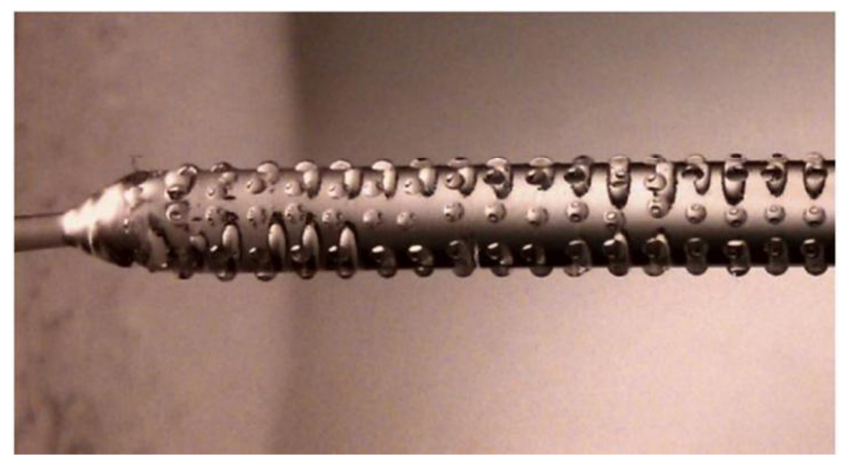

Figure 4. Virtue sirolimus-eluting angioplasty balloon with precise micropores [36].

\section{Conclusion}

The risks associated with foreign implants, such as tissue inflammation, delayed healing, and thrombosis, have recently been attracting more attention. Vascular restoration therapy with no or few foreign implants is the goal for future 
development in percutaneous coronary interventions. Although paclitaxel DEBs have had great success in CADs, especially in in-stent restenosis, challenges still remain: 1) paclitaxel is more toxic and less effective than sirolimus and its analogs, which may cause delayed endothelialization, sustained inflammation, and stent thrombosis; 2) balloon coating has the potential to flake off $(>50 \%)$, decreasing the drug effect and causing downstream embolism; and 3) undefined coating loss greatly influences drug bioavailability. Sirolimus has a superior safety profile compared to paclitaxel, but its pharmacokinetic properties make it a challenging therapeutic candidate for single-time delivery. A packaging technique for sirolimus nano-molecules within particles seems to present a viable option. Nevertheless, both nanoparticle-containing and conventional balloon coatings still face the challenges of releasing downstream particulates from the balloon. Coating firmness, release, and pharmacokinetic drug properties require further study. In addition, paclitaxel DEBs safety concern is only present in the femoropopliteal arteries. Its excellent performance in CAD and other PADs should not be ignored. Moreover, successful application of sirolimus DEBs in CAD should not be transferred directly to PADs, especially in femoropopliteal artery diseases, due to the differences in these disease areas (artery diameter, pathway, and lesion length). Head to head clinical trials of sirolimus and paclitaxel DEBs, DEBs and PTA balloons, and DEBs and DESs should be carried out with strict evaluation criteria and intensive care.

\section{Conflict of Interest}

The authors declare that they have no competing interests.

\section{Acknowledgements}

This work is financially supported by Natural Science Foundation of China (No. 51871020) and National Key R\&D Program of China (2016YFC1102500). The authors thank International Science Editing (http://www.internationalscienceediting.com) for editing this manuscript.

\section{References}

[1] Gray W A, Granada J F. Drug-Coated Balloons for the Prevention of Vascular Restenosis [J]. Circulation. 2010; 121: $2672-2680$.

[2] Taggart D P, Boyle R, de Belder M A, et al. The 2010 ESC/EACTS guidelines on myocardial revascularisation [J]. Heart, 2011, 97 (6): 445-446.

[3] Windecker S, Kolh P, Alfonso F, et al. 2014 ESC/EACTS Guidelines on myocardial revascularization: The Task Force on Myocardial Revascularization of the European Society of Cardiology (ESC) and the European Association for Cardio-Thoracic Surgery (EACTS) Developed with the special contribution of the European Association of Percutaneous Cardiovascular Interventions (EAPCI). Eur Heart J, 2014, 35
(37): 2541-2619.

[4] Neumann F J, Uva M, Ahlsson A, et al. 2018 ESC/EACTS Guidelines on myocardial revascularization [J]. EuroIntervention, 2018, 14 (14): 1435-1534.

[5] Fröhlich GM, Lansky A J, Ko D T, Archangelidi O, De Palma R, Timmis A, Meier P. Drug eluting balloons for de novo coronary lesions-a systematic review and meta-analysis. BMC Medicine. 2013; 11: 123.

[6] Katsanos K, Spiliopoulos S, Kitrou P, Krokidis M, Karnabatidis D. Risk of Death Following Application of Paclitaxel-Coated Balloons and Stents in the Femoropopliteal Artery of the Leg: A Systematic Review and Meta-Analysis of Randomized Controlled Trials. Journal of the American Heart Association. 2018; 7: e011245.

[7] Stone GW, Ellis SG, Cox DA, Hermiller J, O'Shaughnessy C, Mann JT, Turco M, Caputo R, Bergin P, Greenberg J, Popma JJ, Russell ME. One-year clinical results with the slow-release, polymer-based, paclitaxel-eluting TAXUS stent: the TAXUS-IV trial. Circulation. 2004; 110: 1942-1947.

[8] Daemen J, Wenaweser P, Tsuchida K, Abrecht L, Vaina S, Morger C, Kukreja N, Jüni $P$, Sianos G, Hellige G, van Domburg RT, Hess OM, Boersma E, Meier B, Windecker S, Serruys PW. Early and late coronary stent thrombosis of sirolimus-eluting and paclitaxel-eluting stents in routine clinical practice: data from a large two-institutional cohort study. Digest of the World Core Medical Journals. 2007; 369: 667-678.

[9] Stone GW, Ellis SG, Colombo A, Grube E, Popma JJ, Uchida T, Bleuit JS, Dawkins KD, Russell ME. Long-term safety and efficacy of paclitaxel-eluting stents final 5-year analysis from the TAXUS clinical trial program. JACC Cardiovasc Interv. 2011; 4: 530-542.

[10] Milojevic M, Head SJ, Parasca CA, Serruys PW, Mohr FW, Morice MC, Mack MJ, Stahle E, Feldman TE, Dawkins KD, Colombo A, Kappetein AP, Holmes DR Jr. Causes of Death Following PCI Versus CABG in Complex CAD: 5-Year Follow-Up of SYNTAX. J Am Coll Cardiol. 2016; 67: 42-55.

[11] Morice MC, Colombo A, Meier B, Serruys P, Tamburino C, Guagliumi G, Sousa E, Stoll HP. Sirolimus- vs Paclitaxel-Eluting Stents in De Novo Coronary Artery Lesions: The REALITY Trial: A Randomized Controlled Trial. JAMA. 2006; 295: 895-904.

[12] Stone GW, Moses JW, Ellis SG, Schofer J, Dawkins KD, Morice MC, Colombo A, Schampaert E, Grube E, Kirtane AJ, Cutlip DE, Fahy M, Pocock SJ, Mehran R, Leon MB. Safety and Efficacy of Sirolimus- and Paclitaxel-Eluting Coronary Stents. N Engl J Med. 2007; 356: 998-1008.

[13] Gongora CA, Shibuya M, Wessler JD, McGregor J, Tellez A, Cheng Y, Conditt GB, Kaluza GL, Granada JF. Impact of paclitaxel dose on tissue pharmacoki- netics and vascular healing: a comparative drug-coated balloon study in the familial hypercholesterolemic swine model of superficial femoral in-stent restenosis. JACC Cardiovasc Interv. 2015; 8: $1115-1123$

[14] Granada JF, Stenoien M, Buszman PP, Tellez A, Langanki D, Kaluza GL, Leon MB, Gray W, Jaff MR, Schwartz RS. Mechanisms of tissue uptake and retention of paclitaxel-coated balloons: impact on neointimal proliferation and healing. Open Heart. 2014; 1: e000117. 
[15] Secemsky EA, Kundi H, Weinberg I, Jaff MR, Krawisz A, Parikh SA, Beckman JA, Mustapha J, Rosenfield K. Association of Survival With Femoropopliteal Artery Revascularization With Drug-Coated Devices. JAMA Cardiol. 2019.

[16] Schneider PA, Laird JR, Doros G, Gao Q, Ansel G, Brodmann M, Micari A, Shishehbor MH, Tepe G, Zeller T. Mortality Not Correlated With Paclitaxel Exposure: An Independent Patient-Level Meta-Analysis of a Drug-Coated Balloon. J Am Coll Cardiol. 2019; 73: 2550-2563.

[17] Anantha-Narayanan M, Shah SM, Jelani QU, Garcia S, Ionescu C, Regan C. Mena-Hurtado CDrug-coated balloon versus plain old balloon angioplasty in femoropopliteal disease: An updated meta-analysis of randomized controlled trials. Catheter Cardiovasc Interv. 2019.

[18] Albrecht T, Schnorr B, Kutschera M, Waliszewski MW. Two-Year Mortality After Angioplasty of the Femoro-Popliteal Artery with Uncoated Balloons and Paclitaxel-Coated Balloons-A Pooled Analysis of Four Randomized Controlled Multicenter Trials. Cardiovasc Intervent Radiol. 2019; 42: 949-955.

[19] U. S. Food and Drug Administration. Treatment of peripheral arterial disease with paclitaxel-coated balloons and paclitaxel-eluting stents potentially associated with increased mortality-Letter to health care providers. Published on: August 7, 2019. Available at: https://www.fda.gov/medical-devices/letters-health-care-provi ders/august-7-2019-update.

[20] Kastrati A, Dibra A, Eberle S, Mehilli J, Suárez de Lezo J, Goy JJ, Ulm K, Schömig A. Sirolimus-eluting stents vs paclitaxel-eluting stents in patients with coronary artery disease: meta-analysis of randomized trials. JAMA. 2005; 294: 819-825.

[21] Schömig A, Dibra A, Windecker S, Mehilli J, Suárez de Lezo J, Kaiser C, Park SJ, Goy JJ, Lee JH, Di Lorenzo E, Wu J, Jüni P, Pfisterer ME, Meier B, Kastrati A. A meta-analysis of 16 randomized trials of sirolimus-eluting stents versus paclitaxel-eluting stents in patients with coronary artery disease. J Am Coll Cardiol. 2007; 50: 1373-1380.

[22] Stone GW, Midei M, Newman W, Sanz M, Hermiller JB, Williams J, Farhat N, Mahaffey KW, Cutlip DE, Fitzgerald PJ, Sood P, Su X, Lansky AJ. Comparison of an everolimuseluting stent and a paclitaxel-eluting stent in patients with coronary artery disease: a randomized trial. JAMA. 2008; 299: 1903-1913.

[23] Koltin Y, Faucette L, Bergsma DJ, Levy MA, Cafferkey R, Koser PL, Johnson RK, Livi GP. Rapamycin sensitivity in Saccharomyces cerevisiae is mediated by a peptidyl-prolyl cis-trans isomerase related to human FK506-binding protein. Mol Cell Biol. 1991; 11: 1718-1723.

[24] Marx SO, Jayaraman T, Go LO, Marks AR. Rapamycin-FKBP inhibits cell cycle regulators of proliferation in vascular smooth muscle cells. Circ. Res. 1995; 76: 412-417.

[25] Rao S, Krauss NE, Heerding JM, Swindell CS, Ringel I, Orr GA, Horwitz SB. 3'-(p-Azidobenzamido)taxol photolabels the
N-terminal 31 amino acids of $\beta$-tubulin. J. Biol. Chem. 1994; 269: $3132-3134$.

[26] Rowinsky EK, Donehower RC. Paclitaxel (Taxol). N Engl J Med. 1995; 332: 1004-1014.

[27] Heldman AW, Cheng L, Jenkins GM, Heller PF, Kim DW, Ware M Jr, Nater C, Hruban RH, Rezai B, Abella BS, Bunge KE, Kinsella JL, Sollott SJ, Lakatta EG, Brinker JA, Hunter WL, Froehlich JP. Paclitaxel stent coating inhibits neointimal hyperplasia at 4 weeks in a porcine model of coronary restenosis. Circulation. 2001; 103: 2289-2295.

[28] Lemos PA, Farooq V, Takimura CK, Gutierrez PS, Virmani R, Kolodgie F, Christians U, Kharlamov A, Doshi M, Sojitra P, van Beusekom HM, Serruys PW. Emerging technologies: polymer-free phospholipid encapsulated sirolimus nanocarriers for the controlled release of drug from a stent-plus-balloon or a stand-alone balloon catheter. EuroIntervention. 2013; 9: 148-56.

[29] Sojitra P, Yazdani S, Otsuka F, Doshi M, Kolodgie F, Virmani R CRT-123 a novel Nano particle sirolimus delivery via coated balloon. JACC Cardiovasc Interv. 2013; 6: S40.

[30] Dani S, Shah D, Sojitra P, Parikh K, Shetty R, di Palma G, Cortese B. A novel nanocarrier sirolimus-coated balloon for coronary interventions: 12-Month data from the Nanoluté Registry. Cardiovasc Revasc Med. 2019; 20: 235-240.

[31] Dani S, Parikh K, Pillai P K N, Shetty R, Hiremath J, Shah D. CRT-100.84 Long-term Clinical Outcomes After the Treatment of Coronary Stenosis With Sirolimus-coated Balloon Angioplasty: Results From NANOLUTE Real-World Registry. Jacc Cardiovascular Interventions. 2018; 11: S24.

[32] Clever YP, Peters D, Calisse J, Bettink S, Berg MC, Sperling C, Stoever M, Cremers B, Kelsch B, Böhm M, Speck U, Scheller B. Novel Sirolimus-Coated Balloon Catheter. Circulation: Cardiovascular Interventions. 2016; 9: e003543.

[33] Mohd AR, Ali SAKM, Azman WAW, Kiam TO, Bang HL, Scheller B. TCTAP A-001 Treatment of Coronary DES Restenosis with a Sirolimus or Paclitaxel Coated Balloon. Journal of the American College of Cardiology. 2018; 71: S1.

[34] Elicker R J, Shulze J E, Ahlering M T, et al. TCT-843 Preclinical Evaluation of the SELUTION Sirolimus Drug Coated Balloon in a Porcine Coronary Overstretch Model [J]. Journal of the American College of Cardiology, 2016, 68 (18): B340-B341.

[35] Granada JF, Tellez A, Baumbach WR, Bingham B, Keng YF, Wessler J, Conditt G, McGregor J, Stone G, Kaluza GL, Leon MB. In vivo delivery and long-term tissue retention of nanoencapsulated sirolimus using a novel porous balloon angioplasty system. EuroIntervention. 2016; 12: 740-747.

[36] Verheye S, Vrolix M, Kumsars I, Erglis A, Sondore D, Agostoni P, Cornelis K, Janssens L, Maeng M, Slagboom T, Amoroso G, Jensen LO, Granada JF, Stella P. The SABRE Trial (Sirolimus Angioplasty Balloon for Coronary In-Stent Restenosis): Angiographic Results and 1-Year Clinical Outcomes. Jacc Cardiovascular Interventions. 2017; 10: 2029-2037. 